\title{
ASO Visual Abstract: Non-small Cell Lung Cancer Patients with a High Predicted Risk of Irradical Resection-can Chemoradiotherapy Offer Similar Survival?
}

W. Hugo van Joolingen, BSc ${ }^{1}$, Marnix J. A. Rasing, MD ${ }^{1}$, Max Peters, MD, PhD ${ }^{1}$, Anne S. R. van Lindert, MD $^{2}$, Linda M. de Heer, MD, PhD $^{3}$, Mieke J. Aarts, PhD $^{4}$, Joost J. C. Verhoeff, MD, PhD ${ }^{1}$, and Peter S. N. van Rossum, MD, PhD $^{1}$

${ }^{1}$ Department of Radiation Oncology, University Medical Center Utrecht, Utrecht, The Netherlands; ${ }^{2}$ Department of Pulmonology, University Medical Center Utrecht, Utrecht, The Netherlands; ${ }^{3}$ Department of Cardiothoracic Surgery, University Medical Center Utrecht, Utrecht, The Netherlands; ${ }^{4}$ Netherlands Cancer Registry, Netherlands Comprehensive Cancer Organization, Utrecht, The Netherlands

Patients with NSCLC with a high predicted risk of irradical resection (per an internationally validated nomogram) treated with surgery were matched to patients who received chemoradiotherapy. Surgery yielded superior overall survival. Additional factors besides the nomogram should dictate treatment decision-making (https://doi.org/ 10.1245/s10434-021-10982-3).

\section{Non-Small Cell Lung Cancer Patients With a High Predicted Risk} of Irradical Resection - Can Chemoradiotherapy Offer Similar Survival?

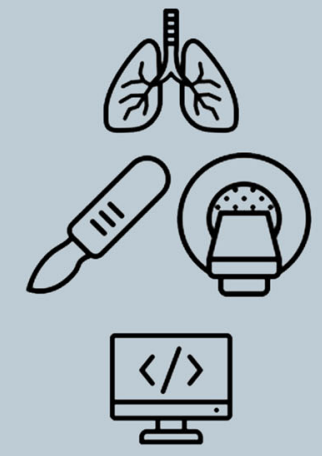

NSCLC patients with a high predicted risk for irradical resection

Treated with either surgery or chemoradiation therapy

Matching of surgery patients to comparable chemoradiation patients

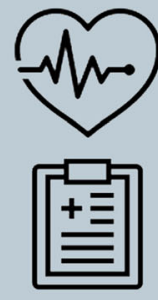

Overall survival in the surgery group superior to the CRT group

Additional factors besides the used nomogram should dictate treatment decision making
(C) Society of Surgical Oncology 2021

J. J. C. Verhoeff, MD, PhD

e-mail: J.J.C.Verhoeff-10@umcutrecht.nl

P. S. N. van Rossum, MD, PhD

e-mail: P.S.N.vanRossum-2@umcutrecht.nl
FUNDING No external funding source was involved in this investigation.

DISCLOSURES The authors have no conflicts of interest relevant to this work.

Publisher's Note Springer Nature remains neutral with regard to jurisdictional claims in published maps and institutional affiliations. 